\title{
Impact of hydroxyethyl starch 70/0.5 on acute kidney injury after gastroenterological surgery
}

\author{
Takeshi Umegaki, Takeo Uba, Chisato Sumi, Sachiyo Sakamoto, \\ Sachiko Jomura, Kiichi Hirota, and Koh Shingu \\ Department of Anesthesiology, Hirakata Hospital, Kansai Medical University, Osaka, Japan
}

\begin{abstract}
Background: Previous studies reported a higher mortality risk and a greater need for renal replacement therapy in patients administered hydroxyethyl starch (HES) rather than other fluid resuscitation preparations. In this study, we investigated the association between 6\% HES 70/0.5 use and postoperative acute kidney injury (AKI) in gastroenterological surgery patients.

Methods: We conducted retrospective full-cohort and propensity-score-based analyses of patients who underwent gastroenterological surgery between June 2011 and August 2013 in a Japanese university hospital. The study sample comprised $66 \mathrm{AKI}$ and 2,152 non-AKI patients in the full-cohort analysis and $35 \mathrm{AKI}$ and 1,269 non-AKI patients in the propensity-score-based analysis. Propensity scores were calculated using an ordered logistic regression model in which the dependent variable comprised three groups based on HES infusion volumes $(0,1-999$, and $\geq 1,000 \mathrm{ml})$. The association between HES groups and postoperative AKI incidence was analyzed using multiple logistic regression models. Other candidate independent variables included patient characteristics and intraoperative measures.

Results: In the full-cohort analysis, 40 (60.6\%) AKI patients were diagnosed as "risk," 15 (22.7\%) as "injury," and 11 (16.7\%) as "failure." In the propensity-score-based analysis, the corresponding values were 22 (62.9\%), 8 (22.9\%), and 5 (14.3\%). There was no significant association between total infused HES and postoperative AKI incidence in either the full-cohort or the propensity-score-based analysis ( $\mathrm{P}=0.168$ and $\mathrm{P}=0.42$, respectively).

Conclusions: AKI incidence was not associated with clinical 6\% HES 70/0.5 administration in gastroenterological surgery patients treated at a single center.
\end{abstract}

Key Words: Acute kidney injury, Gastroenterological surgery, Hydroxyethyl starch.

Corresponding author: Takeshi Umegaki, M.D., Ph.D.

Department of Anesthesiology, Hirakata Hospital, Kansai Medical

University, 2-3-1 Shin-machi, Hirakata, Osaka 573-1191, Japan

Tel: 81-72-804-0100, Fax: 81-72-804-2785

E-mail: umegakit@hirakata.kmu.ac.jp

Received: December 11, 2015.

Revised: February 11, 2016.

Accepted: March 2, 2016.

Korean J Anesthesiol 2016 October 69(5): 460-467 http://dx.doi.org/10.4097/kjae.2016.69.5.460

\section{Introduction}

According to a report from Japan's National Clinical Database, approximately 950,000 gastroenterological surgeries were performed throughout the country between 2011 and 2013 [1]. In these surgeries, hydroxyethyl starch (HES) was the most frequently used volume expander to maintain circulating plasma volume in patients with hemorrhage, while also reducing the need for albumin products.

Previous studies examined the use of HES in patients with severe sepsis and those admitted to intensive care units [2-4]. In both groups, a higher mortality risk and a greater need for renal replacement therapy were identified in patients administered

(c) This is an open-access article distributed under the terms of the Creative Commons Attribution Non-Commercial License (http://creativecommons.org/ licenses/by-nc/4.0/), which permits unrestricted non-commercial use, distribution, and reproduction in any medium, provided the original work is properly cited. 
HES rather than another fluid resuscitation preparation, such as Ringer's solution or saline. Given the frequent administration of HES in surgical settings, it is important to determine whether it is associated with kidney injury.

Prior to the approval of $6 \%$ HES 130/0.4, one of the most prevalent types of HES in the surgical setting in Japan was $6 \%$ HES 70/0.5 (molecular mass: $70 \mathrm{kDa}$; molar substitution ratio: $0.5)$. Although a previous study conducted in Japan found no evidence of an association between HES use and kidney injury, it was limited to patients with massive hemorrhage [5]. Therefore, in this study, we conducted retrospective full-cohort and propensity-score-based analyses to investigate the potential association between $6 \%$ HES 70/0.5 use and the incidence of acute kidney injury (AKI) in gastroenterological surgery patients treated at a Japanese university hospital.

\section{Materials and Methods}

\section{Study design}

This retrospective study consisted of a single-center cohort analysis and a propensity-score-based analysis targeting patients who had undergone gastroenterological surgery between June 2011 and August 2013 at Hirakata Hospital, Kansai Medical University, Japan. The initial study sample comprised 2,394 surgery patients. During the 2-year study period, 6\% HES 70/0.5 (molecular weight: $70 \mathrm{kDa}$, molar substitution ratio: 0.5) (Hespander $^{\circledR}$; Fresenius Kabi, Tokyo, Japan) was used at our hospital. All data were collected from hospital clinical records and administrative claims data.

Patients were excluded from the analysis if they fulfilled any of the following criteria: chronic kidney disease (CKD) stage 5; a lack of recorded data for preoperative serum creatinine, preoperative estimated glomerular filtration rate (eGFR), or postoperative serum creatinine; age $<20$ years at admission; and reoperation performed within 1 week of scheduled or emergency surgery.

\section{Patient characteristics}

AKI patients were identified based on their creatinine levels within 7 days after surgery, as defined by the risk, injury, failure, loss, or end-stage kidney disease (RIFLE) criteria introduced by Bellomo et al. [6].

The following patient baseline characteristics were evaluated and compared between the AKI and non-AKI groups: age, sex, body mass index, CKD stage, comorbidities (hypertension and peripheral vascular disease), perioperative medications [nonsteroidal anti-inflammatory drugs (NSAIDs), angiotensin converting enzyme inhibitor, angiotensin II receptor blockers, and diuretics], American Society of Anesthesiologists Physical Status (ASA-PS) classification, scheduled or emergency surgery, surgical site, operation time, estimated blood loss volume, total infused 6\% HES 70/0.5, eGFR, use of NSAIDs during surgery, urine output, total infusion of crystalloids, red blood cell (RBC) transfusion, and total albumin infusion. The outcome measures were serum creatinine levels (preoperative and postoperative, days 1-7) and AKI level (for AKI patients) according to the RIFLE criteria. The eGFR was calculated using the following equation: $194 \times \mathrm{Cr}^{-1.094} \times$ age $^{-0.287}$ (men) and $194 \times \mathrm{Cr}^{-1.094} \times \mathrm{age}^{-0.287} \times$ 0.739 (women).

In 2005, Japan's Ministry of Health, Labour and Welfare recommended a standard HES dose of $20 \mathrm{ml} / \mathrm{kg}$, although the infusion amount could be increased in patients with rapid, massive hemorrhage. It was thus acknowledged that doses $>20 \mathrm{ml} /$ $\mathrm{kg}$ may be required in patients with hemorrhage in whom leakage included a portion of the infused synthetic colloid solution. In our population of gastroenterological surgery patients, some had been administered HES dosages $>1,000 \mathrm{ml}$. We therefore categorized patients into three groups according to the amount of $6 \%$ HES 70/0.5 infused: $0 \mathrm{ml}, 1-999 \mathrm{ml}$, and $\geq 1,000 \mathrm{ml}$. The patients were also categorized according to estimated blood loss volume: < $500 \mathrm{ml}, 500-999 \mathrm{ml}$, and $\geq 1,000 \mathrm{ml}$.

Gastroenterological surgical sites were categorized as follows: laparoscopic upper abdominal surgery, open upper abdominal surgery, laparoscopic colorectal surgery, open colorectal surgery, combination of abdominal and intrathoracic surgery (thoracoabdominal surgery), and superficial surgery. As thoracoabdominal surgeries performed in our hospital are generally thoracotomies or laparotomies, the two approaches were not further distinguished. The level of AKI was evaluated based on the eGFR and by using the RIFLE criteria, as described by Endo et al. [5]. Postoperative serum creatinine levels were recorded daily for 7 days after the index surgery and included data with missing values.

\section{Statistical analysis}

Continuous variables were calculated as means and standard deviation, and categorical variables as percentages. Differences between AKI and non-AKI patients were compared in univariate analyses using Student's t-test for continuous variables and the $\chi^{2}$ test for categorical variables. $\mathrm{P}<0.05$ was considered to indicate statistical significance.

To calculate the propensity score for $6 \%$ HES 70/0.5 administration, we developed an ordered logistic regression model using the three HES groups as the dependent variable and emergency surgery and estimated blood loss as the independent variable. The propensity-score matching function in SPSS for Windows software (version 22.0, IBM Japan, Ltd., Tokyo, Japan) was used 
to calculate the expected $6 \%$ HES $70 / 0.5$ groups, with patients in the observed and the newly calculated expected groups then matched accordingly. All patients successfully matched based on the ordered logistic regression analysis of the observed and expected 6\% HES 70/0.5 groups were included in this sub-analysis.

The association between 6\% HES 70/0.5 use and postoperative AKI incidence was determined using multiple logistic regression analyses in which AKI incidence was the dependent variable and HES and the variables identified as statistically significant in the univariate analysis were the independent variables. Multiple logistic regression analysis was performed by stratifying the independent variables into three groups: (1) the total infused HES and the propensity score for the HES patients, which were incorporated into the model using the forced entry method; (2) patient characteristics, which were incorporated into the model using the forward selection method based on likelihood ratios; and (3) intraoperative measures, which were also incorporated into the model using the forward selection method based on likelihood ratios. A minimum of 10 AKI patients for each independent variable were required in the multiple logistic regression analysis [7]. All analyses were performed using SPSS for Windows (ver. 22.0; IBM Japan Ltd., Tokyo, Japan).

\section{Results}

The patient selection process for the full-cohort and propensity-score-based analyses is presented in Fig. 1. Among the 2,394 gastroenterological surgery patients initially included in this study, 2,218 were eligible for the analysis. Of these, 66 (3.0\%) AKI patients (AKI group) were included in the full-cohort analysis: 40 (60.6\%) patients categorized as "risk," 15 (22.7\%) as "injury" and $11(16.7 \%)$ as "failure" based on the RIFLE criteria. In the full-cohort analysis, the incidence of AKI in the HES groups $0 \mathrm{ml}, 1-999 \mathrm{ml}$, and $\geq 1,000 \mathrm{ml}$ was $3.2 \%, 2.7 \%$, and $2.9 \%$, respectively $(\mathrm{P}=0.83)$.

According to the propensity scores of the three HES groups, 35 AKI patients and 1,269 non-AKI patients were matched between the observed and expected groups. Thus, there were 926 matched patients in the $0 \mathrm{ml}$ HES group, 80 matched patients in the 1-999 $\mathrm{ml}$ HES group, and 298 matched patients in the $\geq 1,000$ $\mathrm{ml}$ HES group. Among the matched patients, the incidence of AKI in the three HES groups was $2.5 \%, 0 \%$, and $4.0 \%$, respectively $(\mathrm{P}=0.11)$. Thus, the RIFLE criteria results were similar to those of the full-cohort analysis.

Patient characteristics and outcomes are shown in Table 1. The differences between the AKI and non-AKI patients in the full-cohort analysis were significant for the following variables: sex, CKD stage, use of preoperative diuretics, ASA-PS classification, emergency surgery, surgical site, estimated blood loss volume, total crystalloids infusion, total RBC transfusion, and total albumin infusion. In the propensity-score-based analysis, the differences between the AKI and non-AKI patients were significant for ASA-PS classification, scheduled or emergency surgery, estimated blood loss, use of NSAIDs during surgery, and total albumin infusion. The difference in creatinine levels between the two groups were significant in both the full-cohort and

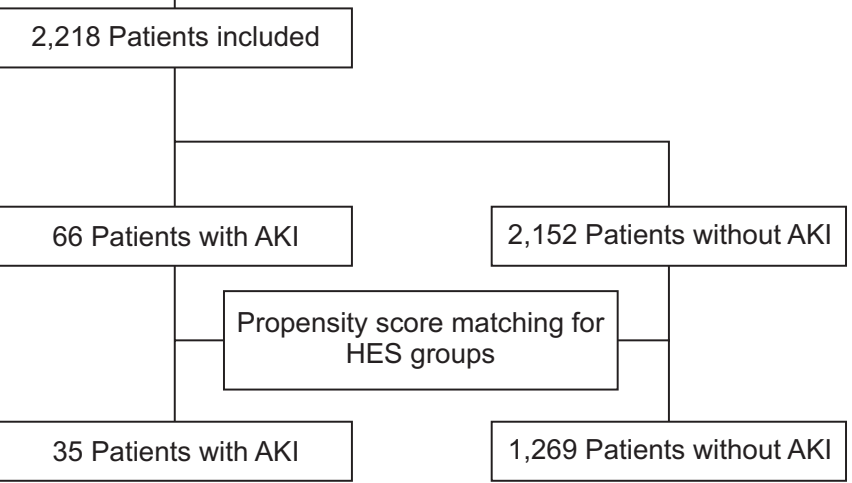

Fig. 1. Patient selection process for this study. CKD: chronic kidney disease, eGFR: estimated glomerular filtration rate, AKI: acute kidney injury, HES: hydroxyethyl starch. 
Table 1. Patient Characteristics and Outcomes

\begin{tabular}{|c|c|c|c|c|c|c|}
\hline & \multicolumn{3}{|c|}{ Full cohort analysis } & \multicolumn{3}{|c|}{ Propensity score-based analysis } \\
\hline & $\begin{array}{l}\text { AKI patients } \\
\quad(\mathrm{n}=66)\end{array}$ & $\begin{array}{l}\text { Non-AKI patients } \\
\quad(\mathrm{n}=2152)\end{array}$ & $P$ value & $\begin{array}{l}\text { AKI patients } \\
\quad(\mathrm{n}=35)\end{array}$ & $\begin{array}{l}\text { Non-AKI patients } \\
\quad(\mathrm{n}=1269)\end{array}$ & $P$ value \\
\hline \multicolumn{7}{|l|}{ Patient characteristics } \\
\hline Age (yr) & $68.7 \pm 12.3$ & $66.2 \pm 12.0$ & 0.09 & $65.6 \pm 14.0$ & $64.9 \pm 12.6$ & 0.73 \\
\hline Male, no. (\%) & $48(72.7)$ & $1274(59.2)$ & 0.03 & $23(65.7)$ & $731(57.6)$ & 0.34 \\
\hline Body mass index $\left(\mathrm{kg} / \mathrm{m}^{2}\right)$ & $21.1 \pm 8.2$ & $22.4 \pm 24.7$ & 0.67 & $19.6 \pm 9.5$ & $22.1 \pm 5.5$ & 0.14 \\
\hline \multicolumn{7}{|l|}{ CKD stage, no. (\%) } \\
\hline $1(90 \leq \mathrm{eGFR})$ & $16(24.2)$ & $435(20.2)$ & \multirow{4}{*}{$<0.01$} & $15(42.9)$ & $778(61.3)$ & \multirow{4}{*}{0.06} \\
\hline $2(60 \leq \mathrm{eGFR}<90)$ & $26(39.4)$ & $1289(59.9)$ & & $11(31.4)$ & $264(20.8)$ & \\
\hline $3(30 \leq \mathrm{eGFR}<60)$ & $20(30.3)$ & $394(18.3)$ & & $7(20.0)$ & $207(16.3)$ & \\
\hline $4(15 \leq \mathrm{eGFR}<30)$ & $4(6.1)$ & $34(1.6)$ & & $2(5.7)$ & $20(1.6)$ & \\
\hline Preoperative eGFR (ml/min/1.73 m²) & $77.9 \pm 44.8$ & $75.5 \pm 21.8$ & 0.67 & $87.4 \pm 49.5$ & $76.4 \pm 21.6$ & 0.20 \\
\hline \multicolumn{7}{|l|}{ Comorbidity } \\
\hline Hypertension & $35(53.0)$ & $918(42.7)$ & 0.15 & $14(40)$ & $517(40.7)$ & 0.93 \\
\hline Peripheral vascular disease & $10(15.2)$ & $189(8.8)$ & 0.17 & $6(17.1)$ & $102(8.0)$ & 0.06 \\
\hline \multicolumn{7}{|l|}{ Preoperative medication } \\
\hline Non-steroidal anti-inflammatory drugs & $6(9.1)$ & $199(9.2)$ & 0.71 & $4(11.4)$ & $108(8.5)$ & 0.54 \\
\hline Angiotensin converting enzyme inhibitor & $4(6.1)$ & $65(3.0)$ & 0.15 & $1(2.9)$ & $36(2.8)$ & 0.99 \\
\hline Angiotensin II receptor blockers & $13(19.7)$ & $380(17.7)$ & 0.67 & $4(11.4)$ & $212(16.7)$ & 0.41 \\
\hline Diuretics & $6(9.1)$ & $103(4.8)$ & 0.04 & $2(5.7)$ & $59(4.6)$ & 0.77 \\
\hline \multicolumn{7}{|l|}{ ASA-PS classification, no. (\%) } \\
\hline 1 & $2(3.0)$ & $316(14.7)$ & \multirow{4}{*}{$<0.001$} & $1(2.9)$ & $194(15.3)$ & \multirow{4}{*}{$<0.001$} \\
\hline 2 & $37(56.1)$ & $1607(74.7)$ & & $20(57.1)$ & $949(74.8)$ & \\
\hline 3 & $21(31.8)$ & $217(10.1)$ & & $11(31.4)$ & $121(9.5)$ & \\
\hline 4 & $6(9.1)$ & $12(0.6)$ & & $3(8.6)$ & $5(0.4)$ & \\
\hline Emergency surgery, no. (\%) & $18(27.3)$ & $140(6.5)$ & $<0.001$ & $10(28.6)$ & $91(7.2)$ & $<0.001$ \\
\hline \multicolumn{7}{|l|}{ Surgical site, no. (\%) } \\
\hline Laparoscopic upper abdominal surgery & $21(31.8)$ & $794(36.9)$ & \multirow{6}{*}{$<0.001$} & $11(31.4)$ & $490(38.6)$ & \multirow{6}{*}{0.57} \\
\hline Open upper abdominal surgery & $27(40.9)$ & $710(33.0)$ & & $13(37.1)$ & $400(35.1)$ & \\
\hline Laparoscopic colorectal surgery & $12(18.2)$ & $373(17.3)$ & & $7(20.0)$ & $221(17.4)$ & \\
\hline Open colorectal surgery & $4(6.1)$ & $152(7.1)$ & & $2(5.7)$ & $86(6.8)$ & \\
\hline Combination of abdominal and intrathoracic surgery & $0(0)$ & $74(3.4)$ & & $0(0)$ & $43(3.4)$ & \\
\hline Superficial surgery & $2(3.0)$ & $49(2.3)$ & & $2(5.7)$ & $29(2.3)$ & \\
\hline \multicolumn{7}{|l|}{ Intraoperative measures } \\
\hline Operation time (min) & $270.0 \pm 206.9$ & $218.9 \pm 143.4$ & 0.05 & $251.5 \pm 248.2$ & $197.6 \pm 156.0$ & 0.21 \\
\hline Estimated blood loss, no. (\%) & & & & & & \\
\hline$<500 \mathrm{ml}$ & $34(51.5)$ & $1610(74.8)$ & & $20(57.1)$ & $930(73.3)$ & \\
\hline $500-999 \mathrm{ml}$ & $13(19.7)$ & $298(13.8)$ & $<0.001$ & $4(11.4)$ & $142(11.2)$ & 0.04 \\
\hline$\geq 1000 \mathrm{ml}$ & $19(28.8)$ & $244(11.3)$ & & $11(31.4)$ & $197(15.5)$ & \\
\hline Total infused HES, no. (\%) & & & & & & \\
\hline $0 \mathrm{ml}$ & $33(50.0)$ & $1002(46.6)$ & & $23(65.7)$ & $903(71.2)$ & \\
\hline $1-999 \mathrm{ml}$ & $17(25.8)$ & $618(28.7)$ & 0.83 & $0(0)$ & $80(6.3)$ & 0.11 \\
\hline$\geq 1000 \mathrm{ml}$ & $16(24.2)$ & $532(24.7)$ & & $12(34.3)$ & $286(22.5)$ & \\
\hline Use of non-steroidal anti-inflammatory drugs during surgery & $6(9.1)$ & $199(9.2)$ & 0.71 & $4(11.4)$ & $370(29.2)$ & 0.02 \\
\hline Urine output (ml) & $618.2 \pm 732.9$ & $679.1 \pm 737.0$ & 0.51 & $662.0 \pm 868.8$ & $559.6 \pm 697.8$ & 0.40 \\
\hline Total crystalloids infusion (ml) & $4848.5 \pm 4029.5$ & $3488.8 \pm 2540.0$ & 0.01 & $4315.7 \pm 4448.4$ & $3226.2 \pm 2841.3$ & 0.16 \\
\hline Total red blood cell transfusion (ml) & $715.5 \pm 1325.7$ & $184.6 \pm 1305.5$ & $<0.01$ & $729.7 \pm 1553.8$ & $216.6 \pm 1662.8$ & 0.06 \\
\hline Total albumin infusion $(\mathrm{ml})$ & $340.9 \pm 724.1$ & $34.3 \pm 178.4$ & 0.001 & $357.1 \pm 816.4$ & $40.9 \pm 183.5$ & 0.03 \\
\hline Outcome measure & & & & & & \\
\hline Serum creatinine $(\mathrm{mg} / \mathrm{dl})$ & & & & & & \\
\hline Preoperative & $0.88 \pm 0.58$ & $0.78 \pm 0.28$ & & $0.83 \pm 0.55$ & $0.77 \pm 0.28$ & \\
\hline Postoperative day 1 & $1.43 \pm 1.63$ & $0.71 \pm 0.27$ & & $1.17 \pm 1.25$ & $0.71 \pm 0.28$ & \\
\hline Postoperative day 2 & $4.1 \pm 18.9$ & $0.74 \pm 0.31$ & & $1.08 \pm 0.67$ & $0.74 \pm 0.30$ & \\
\hline Postoperative day 3 & $1.5 \pm 1.71$ & $0.68 \pm 0.26$ & $<0.01$ & $1.40 \pm 1.42$ & $0.67 \pm 0.27$ & 0.04 \\
\hline Postoperative day 4 & $3.57 \pm 14.73$ & $0.72 \pm 0.27$ & 0.01 & $5.53 \pm 20.60$ & $0.72 \pm 0.27$ & 0.04 \\
\hline Postoperative day 5 & $1.24 \pm 1.07$ & $0.70 \pm 0.30$ & & $1.08 \pm 0.79$ & $0.70 \pm 0.30$ & \\
\hline Postoperative day 6 & $1.26 \pm 1.44$ & $0.72 \pm 0.32$ & & $1.38 \pm 1.98$ & $0.71 \pm 0.29$ & \\
\hline Postoperative day 7 & $1.36 \pm 1.29$ & $0.74 \pm 0.28$ & & $1.08 \pm 0.65$ & $0.73 \pm 0.28$ & \\
\hline RIFLE criteria, no. (\%) & & & & & & \\
\hline Risk & $40(60.6)$ & & & $22(62.9)$ & & \\
\hline Injury & $15(22.7)$ & & - & $8(22.9)$ & & - \\
\hline Failure & $11(16.7)$ & & & $5(14.3)$ & & \\
\hline
\end{tabular}

Values are presented as means \pm SD for continuous variables, and as the number (percentage) for categorical variables. AKI: acute kidney injury, CKD: chronic kidney disease, eGFR: estimated glomerular filtration rate, ASA-PS: American Society of Anesthesiologists Physical Status, HES: hydroxyethyl starch, RIFLE: Risk, Injury, Failure, Loss, or End-stage kidney disease. 
propensity score-based analyses $(\mathrm{P}<0.01$ and $\mathrm{P}<0.04$, respectively). The mean propensity scores $(95 \% \mathrm{CI})$ in the groups with $0 \mathrm{ml}, 1-999 \mathrm{ml}$, and $\geq 1,000 \mathrm{ml}$ of total infused HES were 0.60 (0.59-0.60), 0.39 (0.38-0.39), and 0.72 (0.69-0.74), respectively. In our series of patients, the maximum amount of administered HES was 4,500 ml; among the four patients administered $\geq 3,000$ $\mathrm{ml}$, one (25\%) patient developed AKI.

\section{Multiple logistic regression analysis of AKI incidence in the full-cohort analysis}

The results of the multiple logistic regression models for the full-cohort analysis are shown in Table 2. The administration of $6 \%$ HES 70/0.5 was not significantly associated with AKI incidence $(\mathrm{P}=0.19)$, but there were associations between AKI incidence and ASA-PS classification, emergency surgery, and to-

Table 2. Results of Multiple Logistic Regression Analysis (Full-cohort Analysis)

\begin{tabular}{|c|c|c|c|}
\hline Independent variable & Odds ratio & $95 \% \mathrm{CI}$ & $P$ value \\
\hline Total infused HES (reference: $0 \mathrm{ml}$ ) & & & 0.19 \\
\hline $1-999 \mathrm{ml}$ & 0.77 & $0.41-1.46$ & 0.42 \\
\hline$\geq 1000 \mathrm{ml}$ & 0.48 & $0.22-1.06$ & 0.07 \\
\hline \multicolumn{4}{|l|}{ Sex (reference: female) } \\
\hline Male & 1.59 & $0.87-2.91$ & 0.13 \\
\hline ASA-PS classification (reference: 1 ) & & & $<0.001$ \\
\hline 2 & 2.54 & $0.60-10.77$ & 0.21 \\
\hline$\geq 3$ & 7.85 & $1.76-34.95$ & $<0.01$ \\
\hline CKD stage (reference: 2 ) & & & 0.05 \\
\hline 1 & 1.36 & $0.69-2.68$ & 0.38 \\
\hline$\geq 3$ & 2.12 & $1.16-3.86$ & 0.01 \\
\hline Surgery (emergency) & 2.66 & $1.36-5.19$ & $<0.01$ \\
\hline Use of preoperative diuretics & 1.41 & $0.57-3.52$ & 0.46 \\
\hline Estimated blood loss (reference: $<500 \mathrm{ml}$ ) & & & 0.02 \\
\hline $500-999 \mathrm{ml}$ & 2.37 & $1.17-4.80$ & 0.02 \\
\hline$\geq 1000 \mathrm{ml}$ & 2.74 & $1.16-6.46$ & 0.02 \\
\hline Surgical site (reference: laparoscopic colorectal surgery) & & & 0.89 \\
\hline Laparoscopic upper abdominal surgery & 0.70 & $0.33-1.48$ & 0.35 \\
\hline Open upper abdominal surgery & 0.73 & $0.35-1.53$ & 0.40 \\
\hline Open colorectal surgery & 0.49 & $0.15-1.66$ & 0.25 \\
\hline Combination of abdominal and intrathoracic surgery* & - & - & - \\
\hline Superficial surgery & 1.00 & $0.18-5.56$ & 0.99 \\
\hline Total crystalloids infusion (ml) & 1.00 & $1.00-1.00$ & 0.47 \\
\hline Total red blood cell transfusion $(\mathrm{ml})$ & 1.00 & $1.00-1.01$ & 0.78 \\
\hline Total albumin infusion $(\mathrm{ml})$ & 1.001 & $1.001-1.002$ & $<0.001$ \\
\hline
\end{tabular}

The Incidence of Acute Kidney Injury was the Dependent Variable $(\mathrm{n}=2218)$. CI: confidence interval, HES: hydroxyethyl starch, ASA-PS: American Society of Anesthesiologists Physical Status, CKD: chronic kidney disease. ${ }^{*}$ There were no patients with acute kidney injury in this category.

Table 3. Results of Multiple Logistic Regression Analysis (Propensity Score-based Analysis) with Acute Kidney Injury Incidence as the Dependent Variable $(\mathrm{n}=1304)$

\begin{tabular}{|c|c|c|c|}
\hline Independent variable & Odds ratio & $95 \%$ CI & P value \\
\hline Total infused HES (reference: $0 \mathrm{ml}$ ) & & & 0.94 \\
\hline $1-999 \mathrm{ml}^{*}$ & - & - & - \\
\hline$\geq 1000 \mathrm{ml}$ & 1.19 & $0.47-3.01$ & 0.72 \\
\hline ASA-PS classification (reference: 1 ) & & & 0.001 \\
\hline 2 & 3.61 & $0.48-27.36$ & 0.21 \\
\hline$\geq 3$ & 12.89 & $1.63-102.06$ & 0.02 \\
\hline Surgery (emergency) & 3.25 & $1.31-8.05$ & 0.01 \\
\hline Use of non-steroidal anti-inflammatory drugs during surgery & 0.50 & $0.17-1.46$ & 0.20 \\
\hline Total albumin infusion (ml) & 1.001 & $1.001-1.002$ & 0.001 \\
\hline
\end{tabular}

CI: confidence interval, HES: hydroxyethyl starch, ASA-PS: American Society of Anesthesiologists Physical Status. ${ }^{*}$ There were no patients with acute kidney injury in this category. 
tal albumin infusion. The regression analysis accounted for their variations among the HES groups. Higher ASA-PS classes were associated with higher odds ratios (ORs) for AKI incidence, and emergency surgery had a higher OR for AKI than scheduled surgery. Estimated blood loss $\geq 500 \mathrm{ml}$ was significantly associated with ORs $>2.3$.

\section{Multiple logistic regression analysis of AKI incidence in the propensity-score-based analysis}

The results of the propensity-score-based analysis are shown in Table 3. Similar to the full-cohort analysis, there was no significant association between the administration of $6 \%$ HES $70 / 0.5$ and AKI incidence $(\mathrm{P}=0.94)$, whereas significantly higher ORs for AKI incidence were determined for ASA-PS classification, emergency surgery, and total albumin infusion, but not for NSAIDs during surgery $(\mathrm{P}=0.20)$.

\section{Discussion}

Our study found no evidence of a significant effect of HES administration on AKI incidence after gastroenterological surgery, as the incidence in patients administered $\geq 1,000 \mathrm{ml}$ was similar (about $0.3 \%$ lower) to that in patients not administered HES. Because the molecular mass and degree of substitution of $6 \%$ HES 70/0.5 are relatively low, the effect time of this plasma augmenter is relatively short, such that it is unlikely to influence postoperative kidney status. Our results are consistent with those of some, but not all, previous studies evaluating other surgical settings [5,8]. For example, Mårtensson and Bellomo [9] reported that intraoperative HES is harmful to postoperative renal function. Conversely, in a retrospective analysis of 846 surgical patients with massive hemorrhage ( $\geq 1,000 \mathrm{ml}$ intraoperative blood loss), Endo et al. [5] found no association between $6 \%$ HES 70/0.5 administration and postoperative renal function. Our study also included patients with blood loss volumes of < $1,000 \mathrm{ml}$ and the analyses were based on the categorization of patients according to HES infusion volume and estimated blood loss. In a retrospective study of 31 patients who had survived $\geq$ 1 month after an intraoperative blood loss of $\geq 500 \mathrm{ml}$, Suzuki et al. [10] showed that there was no significant difference between the amount of HES administered to patients who developed AKI and those who did not ( $53 \mathrm{vs.} 55 \mathrm{ml} / \mathrm{kg}$ ); they also failed to identify a correlation between HES dose and changes in serum creatinine. Ahn et al. [11] evaluated the risk of AKI in similar numbers of AKI and non-AKI patients; they concluded that HES should be used with caution in patients with decreased renal function who are undergoing thoracic surgery. Our study results may have been influenced by selection bias regarding renal function.
We also found no evidence of a relationship between perioperative medication and comorbidity. However, this does not necessarily rule out an association between these variables and postoperative AKI because our study focused on the association between intraoperative HES and postoperative AKI, such that a degree of selection bias for these variables may have been introduced.

The postoperative AKI incidence in our study (2.97\%) is within the range reported for non-cardiac and cardiac surgical cases (0.8-14\% and 5-20\%, respectively) [12-16]. In a systematic review conducted by Gillies et al. [17], the incidence of AKI in patients administered HES intraoperatively was 5.4\%, whereas in patients who had not been administered HES it was 3.6\%. Although those authors addressed the impact of HES on AKI incidence, they did not include any studies in which patients received HES 70/0.5 (Hespander), the form administered to our patients. Despite the differences in the molecular mass and molar substitution ratio of HES 70/0.5 vs. other preparations, the incidence of AKI in this study was similar to the incidences reported in that review.

$\mathrm{RBC}$ transfusion is a risk factor for AKI after cardiac surgery $[18,19]$, but an analogous association was not detected in our gastroenterological surgery patients. The multiple logistic regression model of our full-cohort analysis did not show any significant association between AKI and RBC transfusion, nor did the univariate analysis in the propensity-score-based analysis. Our omission of the RBC transfusion as a variable in the latter analysis was in accordance with the purpose of this study, which was to evaluate the association between 6\% HES 70/0.5 and AKI in gastroenterological surgery patients; other factors that may contribute to the development of postoperative AKI were therefore not considered. Thus, whether RBC transfusion is also a risk factor for AKI in other clinical settings remains to be determined.

This study had several limitations that should be taken into account in the interpretation of its findings. First, the ASA-PS classification is a comprehensive evaluation of overall physical status; it does not provide insights into the individual comorbidities of each patient, except for hypertension and peripheral vascular disease. Other studies have shown that the incidence of postoperative AKI is affected by risk factors including male sex, older age, heart disease, hypertension, peripheral vascular disease, diabetes, chronic obstructive pulmonary disease, and hypoalbuminemia [13-16]. Except for hypertension and peripheral vascular disease, these individual comorbidity risk factors were not included as covariates in this study and their potential association with AKI in gastrointestinal surgery patients was therefore not addressed. However, our study did show a significant association between ASA-PS classification and postoperative AKI. By contrast, CKD stage was not a significant factor related 
to AKI incidence. The possibility that different CKD stages may necessitate changes in anesthetic management should be considered, especially in the selection of intravenous infusions and the use of NSAIDs. Although we included intraoperative use of NSAIDs, crystalloid infusion, RBC transfusion, and albumin use, we were unable to account for preoperative medications (except NSAIDs, angiotensin converting enzyme inhibitors, and angiotensin II receptor blockers) due to data limitations. Third, data regarding perioperative patient volume state, such as stroke volume variation (SVV) and pulse pressure variation (PPV), were not available for analysis, nor were data on postoperative urine volume. Although perioperative goal-directed therapy protocols are targeted at achieving hemodynamic optimization, neither SVV nor PPV is routinely monitored at our center, especially in patients undergoing minimally to moderately invasive surgery. We were therefore unable to determine the effect of perioperative hypovolemic state on postoperative AKI. Evaluation using the Clavien-Dindo classification may have provided information on postoperative leakage, infection, or ileus partly caused by hypervolemia and edema, and especially that associated with crystalloid use, whereas colloid administration would have reduced intestinal tract edema. In this study, AKI incidence was only slightly higher in patients who did not receive HES than in those who did. However, our definition of AKI relied only on the serum creatinine component of the RIFLE criteria. The inclusion of the above-cited information may alter the results. Nonetheless, a previous report demonstrated that AKI can be evaluated with the method used in this study [5]. Moreover, although we assumed that increases in blood loss volumes would require the infusion of larger amounts of HES, in patients with hemorrhage a portion of the infused HES may have leaked such that not all of the HES would have been metabolized by the kidneys. Our study differs from a previous study from Japan [5] in that it included blood loss volumes and HES infusion amounts in assessing AKI. Finally, this single-center study included only 66 patients with postoperative AKI vs. 2,152 non-AKI patients. The inclusion of a larger number of these patients in the logistic regression analysis would have increased the statistical power of our study. Our approach, however, was to stratify the independent variables into three different groups, with a minimum of 10 AKI cases for each variable, to achieve an adequate sample size in the final model. The statistical power was 0.94 at an alpha level of 0.05 . Also, while the results indicated a relatively high frequency of AKI among patients who had been administered large quantities of HES (> 3,000 ml), there were only three nonAKI patients and one AKI patient. Our results must therefore be confirmed in a study with a larger sample size. At a volume of 1,000 ml, there was no significant increase in the incidence of AKI in our patients.

In conclusion, both the full-cohort analysis and the propensity-score-based analysis demonstrated a lack of association between clinical 6\% HES 70/0.5 use and postoperative AKI incidence in gastroenterological surgery patients treated in a single center. Randomized clinical trials will be needed to definitively determine whether HES plays a role in the development of postoperative AKI.

\section{Acknowledgments}

The study was approved by the Institutional Ethics Committee of Hirakata Hospital, Kansai Medical University in September, 2015.

\section{References}

1. Konno H, Wakabayashi G, Udagawa H, Unno M, Kunisaki C, Goto M, et al. Annual report of National Clinical Database in Gastroenterological Surgery 2011-2012 (in Japanese). Nihon Shokaki Geka Gakkai Zasshi 2013; 46: 952-63.

2. Perner A, Haase N, Guttormsen AB, Tenhunen J, Klemenzson G, Åneman A, et al. Hydroxyethyl starch 130/0.42 versus Ringer's acetate in severe sepsis. N Engl J Med 2012; 367: 124-34.

3. Myburgh JA, Finfer S, Bellomo R, Billot L, Cass A, Gattas D, et al. Hydroxyethyl starch or saline for fluid resuscitation in intensive care. N Engl J Med 2012; 367: 1901-11.

4. Brunkhorst FM, Engel C, Bloos F, Meier-Hellmann A, Ragaller M, Weiler N, et al. Intensive insulin therapy and pentastarch resuscitation in severe sepsis. N Engl J Med 2008; 358: 125-39.

5. Endo A, Uchino S, Iwai K, Saito K, Sanui M, Takinami M, et al. Intraoperative hydroxyethyl starch 70/0.5 is not related to acute kidney injury in surgical patients: retrospective cohort study. Anesth Analg 2012; 115: 1309-14.

6. Bellomo R, Ronco C, Kellum JA, Mehta RL, Palevsky P. Acute renal failure - definition, outcome measures, animal models, fluid therapy and information technology needs: the Second International Consensus Conference of the Acute Dialysis Quality Initiative (ADQI) Group. Crit Care 2004; 8: R204-12.

7. Peduzzi P, Concato J, Kemper E, Holford TR, Feinstein AR. A simulation study of the number of events per variable in logistic regression analysis. J Clin Epidemiol 1996; 49: 1373-9.

8. Wiesen P, Canivet JL, Ledoux D, Roediger L, Damas P. Effect of hydroxyethylstarch on renal function in cardiac surgery: a large scale 
retrospective study. Acta Anaesthesiol Belg 2005; 56: 257-63.

9. Mårtensson J, Bellomo R. Prevention of renal dysfunction in postoperative elderly patients. Curr Opin Crit Care 2014; 20 : 451-9.

10. Suzuki T, Miyao H, Terui K, Koyama K, Shiibashi M. Fluid therapy with hydroxyethyl starch for massive blood loss during surgery. J Anesth 2010; 24: 418-25.

11. Ahn HJ, Kim JA, Lee AR, Yang M, Jung HJ, Heo B. The risk of acute kidney injury from fluid restriction and hydroxyethyl starch in thoracic surgery. Anesth Analg 2016; 122: 186-93.

12. Hutchens MP, Dunlap J, Hurn PD, Jarnberg PO. Renal ischemia: does sex matter? Anesth Analg 2008; 107: 239-49.

13. Kim CS, Oak CY, Kim HY, Kang YU, Choi JS, Bae EH, et al. Incidence, predictive factors, and clinical outcomes of acute kidney injury after gastric surgery for gastric cancer. PLoS One 2013; 8: e82289.

14. Conlon PJ, Stafford-Smith M, White WD, Newman MF, King S, Winn MP, et al. Acute renal failure following cardiac surgery. Nephrol Dial Transplant 1999; 14: 1158-62.

15. Mangano CM, Diamondstone LS, Ramsay JG, Aggarwal A, Herskowitz A, Mangano DT. Renal dysfunction after myocardial revascularization: risk factors, adverse outcomes, and hospital resource utilization. The Multicenter Study of Perioperative Ischemia Research Group. Ann Intern Med 1998; 128: 194-203.

16. Chertow GM, Lazarus JM, Christiansen CL, Cook EF, Hammermeister KE, Grover F, et al. Preoperative renal risk stratification. Circulation 1997; 95: 878-84.

17. Gillies MA, Habicher M, Jhanji S, Sander M, Mythen M, Hamilton M, et al. dence of postoperative death and acute kidney injury associated with i.v. 6\% hydroxyethyl starch use: systematic review and meta-analysis. Br J Anaesth 2014; 112: 25-34.

18. Karkouti K, Wijeysundera DN, Yau TM, Callum JL, Cheng DC, Crowther M, et al. Acute kidney injury after cardiac surgery: focus on modifiable risk factors. Circulation 2009; 119: 495-502.

19. Karkouti K, Wijeysundera DN, Yau TM, McCluskey SA, Chan CT, Wong PY, et al. Influence of erythrocyte transfusion on the risk of acute kidney injury after cardiac surgery differs in anemic and nonanemic patients. Anesthesiology 2011; 115: 523-30. 